\title{
Influence of drying methods on the physicochemical properties and nutritional composition of instant Tremella fuciformis
}

\author{
Yibin $\mathrm{LI}^{1,2}$ (D), Junchen $\mathrm{CHEN}^{1,2}$, Pufu LAI ${ }^{1 *}$, Baosha TANG ${ }^{1,2}$, Li WU ${ }^{1,2}$
}

\begin{abstract}
Instant Tremella fuciformis is ready to eat after adding hot water and is a delicious edible mushroom food. However, the drying method affects the quality of product. The present work evaluated the effects of freeze drying (FD), microwave drying (MD), and hot air drying (HAD) on shrinkage ratio, rehydration ratio, microstructure, polysaccharide and free amino acids of instant Tremella fuciformis. These three drying methods significantly changed the color and reduced the total amount of amino acids of dried products. FD sample possessed a three-dimensional network with porous, loose and large voids, so it had a slighter shrinkage and a better rehydration effect compared with the MD and HAD one. The polysaccharide content, uronic acid content and soup's viscosity of FD products were significantly higher than MD and HAD. Therefore, FD was more suitable for obtaining high-quality instant Tremella fuciformis products than MD and HAD.
\end{abstract}

Keywords: freeze drying; color; microstructure; polysaccharide; free amino acids.

Practical Application: Evaluation of the quality for instant Tremella fuciformis products by three drying methods.

\section{Introduction}

Tremella fuciformis (T. fuciformis), also known as white fungus and snow fungus, is a species of edible and medicinal fungus in Asia. It has developed as one of the widely cultivated edible fungi in China and other countries in Asia. In 2018, production of T. fuciformis in China reached 360,000 tons, accounting for more than $90 \%$ of world production. T. fuciformis is rich in active polysaccharides (Wu et al., 2019). In recent years, many reports had shown that $T$. fuciformis polysaccharides possessed various bioactivities (Wu et al., 2019), including antioxidation, anti-tumor (Chen, 2010), anti-aging (Wen et al., 2016), immunomodulatory (Zhou et al., 2018), and anti-inflammator (Lee et al., 2016; Yang et al., 2018).

Convenience foods have become a popular food due to the fast-paced lifestyle of modern society (Ricci et al., 2018). T. fuciformis is a traditional food, but its cooking process is time consuming and difficult to adapt to the needs of modern consumers. As a convenience food, the instant T. fuciformis product can be eaten after adding hot water. In a short period of time, the consistency and flavor of the instant T. fuciformis product's soup reaches the taste of the cooking of T. fuciformis for a long time. After adding 100 times of weight of hot water, the good quality instant T. fuciformis product can absorb 10 times of water in 10 minutes, and the viscosity value of the soup exceeds $45 \mathrm{mPa} \cdot \mathrm{s}$. Therefore, the development of instant $T$. fuciformis can meet the needs of consumers in large cities, where modern lifestyles tend to constraint their available time.

Drying is a widely used technology in convenience foods processing. Moisture migration during drying is controlled by the complex internal structure of the food (Singh \& Heldman, 2014). The phytochemical and physical changes of food during the drying process directly affect the quality of the final product. Various studies have attempted using product's quality as a criterion to evaluate different drying methods. Nemzer et al. (2018) compared phytochemical and physical properties of blueberries, tart cherries, strawberries, and cranberries as affected by 3 drying methods (hot-air drying, freeze drying and refractance window drying. They concluded that the quality retention in the dried fruits was related to drying method specific. Sehrawat et al. (2018) compared the effects of low-pressure superheated drying, vacuum drying and hot air drying on mango cubes quality parameters, in order to develop mango snacks. The products dried using low-pressure superheated drying had higher retention of ascorbic acid, $\beta$-carotene, total phenol content, compared to those produced by using vacuum drying and hot air drying. Ozcan-Sinir et al. (2019) revealed that microwave dried kumquat slices had the highest antioxidant activity among microwave $(375 \mathrm{~W})$, hot air (70 and $80^{\circ} \mathrm{C}$ ), and vacuum drying. The high-quality products of instant food require the unique taste of the white fungus, but also preserve the nutrients of the white fungus. Furthermore, the quality of instant $T$. fuciformis is closely related to the processing technology, especially the drying method.

The current study represented the attempt to provide several important quality parameters of instant $T$. fuciformis mushrooms, such as nutrient retention, shrinkage, rehydration rate, color, free amino acid and microstructure, etc., undergoing freeze drying (FD), microwave drying (MD) and hot air drying (HAD). 


\section{Materials and methods}

\subsection{Materials}

Fresh cultivated T. fuciformis mushroom graded according to uniform maturity and size were acquired from a mushroom farm in Youxi County, Fujian Province, China. All mushroom stored in a refrigerator at a temperature of $5 \pm 1{ }^{\circ} \mathrm{C}$ with $90 \%$ relative humidity prior to experimentation. Fruiting body of mushroom was thoroughly washed after removing the yellow roots of T. fuciformis. The mushrooms were added to the distilled water of 1.5 times the weight of the mushrooms, and then were heated to $100^{\circ} \mathrm{C}$ for 5 minutes. The cooked T. fuciformis samples were placed on a stainless steel tray in a weight of $120 \mathrm{~g} \pm 1 \mathrm{~g}$ per part, except that the microwave dried sample was dispensed on a tray of polypropylene material. The sample was spread evenly and the thickness was $10.0 \mathrm{~mm} \pm 2.0 \mathrm{~mm}$. The initial moisture content of sample was $96.2 \pm 1.2 \%(\mathrm{w} / \mathrm{w})$. The hot air dried and microwave dried samples were directly dried, and the lyophilized samples were frozen at $-30 \pm 2{ }^{\circ} \mathrm{C}$ for $8 \mathrm{~h}$ in a deep freezer (DW-40L188, Haier medical and laboratory products Co., Ltd., China) and then dried.

\subsection{Drying methods}

\section{Freeze drying}

The frozen samples in the refrigerator at $-30^{\circ} \mathrm{C}$ were quickly transferred to the pre-cooled freeze dryer (SCIENTZ-30ND freeze dryer, Ningbo Xinzhi Biotechnology Co., Ltd., China). The lyophilizer had a cold trap temperature of $-50^{\circ} \mathrm{C} \pm 2{ }^{\circ} \mathrm{C}$, a vacuum of 10-20 $\mathrm{Pa}$. In previous studies, the effect of lyophilization heating temperature on product quality was discussed. Finally, parameters suitable for food industry production were selected.
The lyophilizer was set to a heating temperature of $50^{\circ} \mathrm{C}$ for $4 \mathrm{~h}$, then $55^{\circ} \mathrm{C}$ for $4 \mathrm{~h}$, and finally $60^{\circ} \mathrm{C}$ for $16 \mathrm{~h}$.

\section{Microwave drying}

A microwave oven (WD900B, Guangdong Galanz Microwave Electric Appliance Co., Ltd. China) with a maximum power output of $900 \mathrm{~W}$ and $2450 \mathrm{MHz}$ was used. The samples, weighing $120 \mathrm{~g} \pm 1 \mathrm{~g}$ and a thickness of $10.0 \pm 2.0 \mathrm{~mm}$, were evenly spread in a single layer over the tray of polypropylene material. The preliminary pre-test found that too high power affected the quality of T. fuciformis product, and if the power was too low, the drying speed was too slow. After pre-testing, the sample was dried under microwave power $540 \mathrm{~W}$ for $5 \mathrm{~min}$, suspended for $30 \mathrm{~s}$, and then cycled by microwave for $1 \mathrm{~min}$ and suspended for $30 \mathrm{~s}$. Drying lasted for 18 minutes until the moisture content of the sample dropped below $8 \%(\mathrm{w} / \mathrm{w})$.

\section{Hot air drying}

The pretreated samples of T. fuciformis were dispensed on stainless steel trays in an amount of $120 \mathrm{~g} \pm 1 \mathrm{~g}$ per part, and the samples were evenly spread with a thickness of $10.0 \pm 2.0 \mathrm{~mm}$. The preliminary pre-tests showed that the hot air drying temperature greater than $60^{\circ} \mathrm{C}$ significantly affected the quality of the white fungus. Hence, the sample was placed in an electric heating constant temperature air drying oven at a temperature of $60^{\circ} \mathrm{C}$ and a wind speed of $2.5 \mathrm{~m} / \mathrm{s}$, and the sample was dried to constant weight for 24 hours.

All dried samples were packaged in aluminum foil bags for further quality analysis. Each experiment was carried out in triplicates. In Figure 1 the schematic procedure about the processing technique of instant T. fuciformis had been depicted.

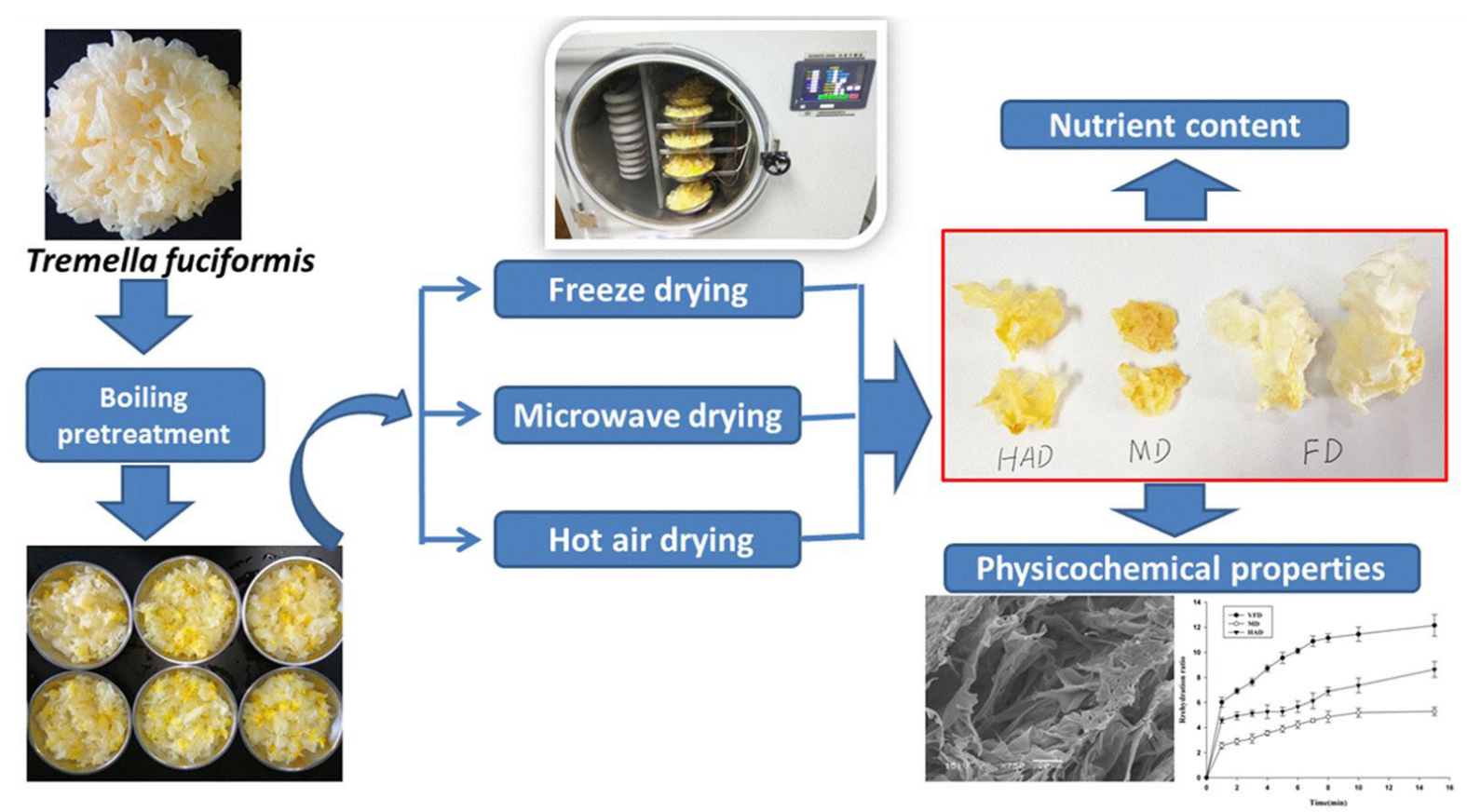

Figure 1. Schematic description about the processing technique of instant T. fuciformis. HAD = hot air dying; MD = microwave drying; $\mathrm{FD}=$ freeze drying. 


\subsection{Analysis methods}

Shrinkage ratio

The shrinkage ratio was measured by a displacement method (Jiang et al., 2017). Glass beads with a diameter of 0.1-0.2 mm were used as a replacement medium. The shrinkage ratio of dried T. fuciformis was calculated as follows (Equation 1):

Shrinkage ratio $=\frac{\mathrm{Vo}-\mathrm{Vd}}{\mathrm{Vo}_{\mathrm{o}}} \times 100 \%$

where: $V_{o}$ and $V_{d}$ refer to the volume $\left(\mathrm{cm}^{3}\right)$ of the original and dried material, respectively.

\section{Rehydration ratio}

The rehydration ratio experiment followed methods similar to Wang et al. (2014). $5 \mathrm{~g}$ of the dried sample was weighed and rehydrated under a constant temperature of $90^{\circ} \mathrm{C}$. The sample was taken out every $1 \mathrm{~min}$, drained for $30 \mathrm{~s}$, and the surface of the T. fuciformis was dried with absorbent paper and weighed. Continue to rehydrate and weigh again after $1 \mathrm{~min}$. Repeat the operation until the T. fuciformis absorbed water for $15 \mathrm{~min}$. Each group of experiments was repeated 3 times and the results were averaged. Formula for calculating the recalculation ratio of Tremella (Equation 2):

Rehydration ratio $=\frac{\mathrm{M}_{2}}{\mathrm{M}_{1}}$

where: $M_{1}$ is the weight of the sample before rehydration; and $M_{2}$ is the weight of the sample after rehydration.

\section{Color measurements}

The sample was pulverized into a powder having a particle diameter of less than $0.5 \mathrm{~mm}$, and then the color analyses were carried out with a colorimeter (NS810, Shenzhen 3NH Technology Co., Ltd., China). The color analyses of the samples before and after drying were recorded in CIE $L^{*}, a^{*}, b^{*}$ values. $L^{*}$ denotes the degree of lightness on 0-100 scale from black to white, $a^{*}$ is the degree of redness $(+)$ to greenness $(-)$, and $b^{*}$ is the degree of yellowness (+) to blueness (-) (Li et al., 2018; Lin et al., 2019). The instrument was standardized by a standard white plate before the measurements. All analyses were performed in triplicate.

Viscosity and polysaccharide content of instant T. fuciformis soup

$3 \mathrm{~g}$ of dried instant $T$. fuciformis was added to $300 \mathrm{~mL}$ of $90{ }^{\circ} \mathrm{C}$ hot water, rehydrated for 15 minutes, and stirred every five minutes. The mixture was filtered through a sieve having a pore size of $0.15 \mathrm{~mm}$ to remove the solid residue, and then the viscosity and polysaccharide content of the filtrate were measured. The viscosity value was tested by a rotary viscometer (NDJ-1, Shanghai Bangxi Instrument Technology Co., Ltd., China). The filtrate was added with 3 times of $95 \%$ ethanol, and allowed to stand in a 4 degree refrigerator for 12 hours, and filtered to obtain a polysaccharide precipitate. The polysaccharide content was determined by the phenol-sulfuric acid method.

\section{Microstructure}

Morphological characteristics of the dried mushroom samples were observed using a scanning electron microscope (JSM-6380LV, Japan Electronics Corporation. Japan). A $1 \mathrm{~mm}$ thick slice of the dried samples was attached to a double-sided adhesive tape mounted on a scanning electron microscope stub, coated with gold in a vacuum evaporator. The scanning electron microscope was operated at $15 \mathrm{kV}$ with magnification of $750 \times$ and $1200 \times$.

\section{Moisture content, protein content, and reducing sugar content}

The moisture content of the T. fuciformis samples was quantified gravimetrically by oven-drying at $105^{\circ} \mathrm{C}$ to constant weight. The protein content of the sample was determined by the Kjeldahl method. The reducing sugar content was measured based on the 3,5-dinitrosalicylic acid (DNS) method, as described in the previous report (Lin et al., 2017; Hu et al., 2019).

\section{Polysaccharide content and uronic acid content}

The polysaccharide of T. fuciformis mushroom was extracted with hot water at $90^{\circ} \mathrm{C}$ for 60 minutes, and then collected by with $95 \%$ ethanol. The content of polysaccharide was measured using the phenol-sulfuric acid method using D-glucose as a standard. The uronic acid content was measured by 3-hydroxydiphenyl assay using glucuronic acid as a reference material (Wu et al., 2014).

\section{Free amino acid analysis}

The free amino acid was determined according to the National Food Safety Standard of China (GB 5009.124-2016). A $1 \mathrm{~g}$ sample was placed in a $6 \mathrm{~mol} / \mathrm{L} \mathrm{HCl}$ solution, and then hydrolyzed at $110{ }^{\circ} \mathrm{C}$ for $24 \mathrm{~h}$. Finally, the free amino acid composition and content of the sample were determined by an amino acid analyzer (835-50, Hitachi, Japan).

\section{Results and discussion}

\subsection{Effects of different drying methods on shrinkage ratio of dried instant T. fuciformis}

The shrinkage rate reflects the changes in the structure and cell arrangement of food during drying, which is an important indicator for the quality evaluation of dried product. The consequence of shrinkage in dried food will affect product color, size, structure, aroma and taste (Nguyen et al., 2018). The order of the shrinkage rate of the dried instant T. fuciformis products was as follows: microwave drying $>$ hot air drying $>$ freeze drying (Table 1). There were significant differences in shrinkage among FD, $\mathrm{MD}$ and HAD processing, and FD products had the smallest shrinkage value of $16.54 \%$.

This may be because the moisture in the T. fuciformis material is directly sublimated by the ice crystal during the freeze-drying process. And the original shape of T. fuciformis is basically maintained, thereby forming a porous structure. Meanwhile, the initial moisture content of the T. fuciformis sample is more than $90 \%$, and the viscoelasticity of the amorphous matrix is lowered. Hence part of the structure of the product 
Table 1. Shrinkage and color change of instant T. fuciformis dried by FD, MD and HAD.

\begin{tabular}{|c|c|c|c|c|}
\hline \multirow{2}{*}{ Drying methods } & \multirow{2}{*}{ Shrinking ratio (\%) } & \multicolumn{3}{|c|}{ Color } \\
\hline & & $L^{*}$ & $a^{*}$ & $b^{*}$ \\
\hline FD & $16.54 \pm 0.98^{c}$ & $81.50 \pm 1.13^{a}$ & $1.65 \pm 0.36^{c}$ & $14.40 \pm 1.16^{c}$ \\
\hline $\mathrm{MD}$ & $68.36 \pm 1.52^{\mathrm{a}}$ & $69.99 \pm 1.06^{c}$ & $5.78 \pm 0.34^{\mathrm{a}}$ & $23.56 \pm 0.84^{\mathrm{a}}$ \\
\hline Undried & l & $49.50 \pm 1.21^{\mathrm{d}}$ & $-1.25 \pm 0.22^{\mathrm{d}}$ & $1.43 \pm 0.27^{\mathrm{d}}$ \\
\hline
\end{tabular}

Data are presented as the mean $\pm \mathrm{SD}(\mathrm{n}=3)$. Values with different letters in the same column differ significantly $(p<0.05)$. In the CIE-Lab system, $L^{*}$ denotes lightness on 0 -100 scale from black to white; $a^{*},(+)$ red or $(-)$ green; and $b^{*},(+)$ yellow or $(-)$ blue. $\mathrm{FD}=$ freeze drying; $\mathrm{MD}=$ microwave drying; $\mathrm{HAD}=$ hot air dying.
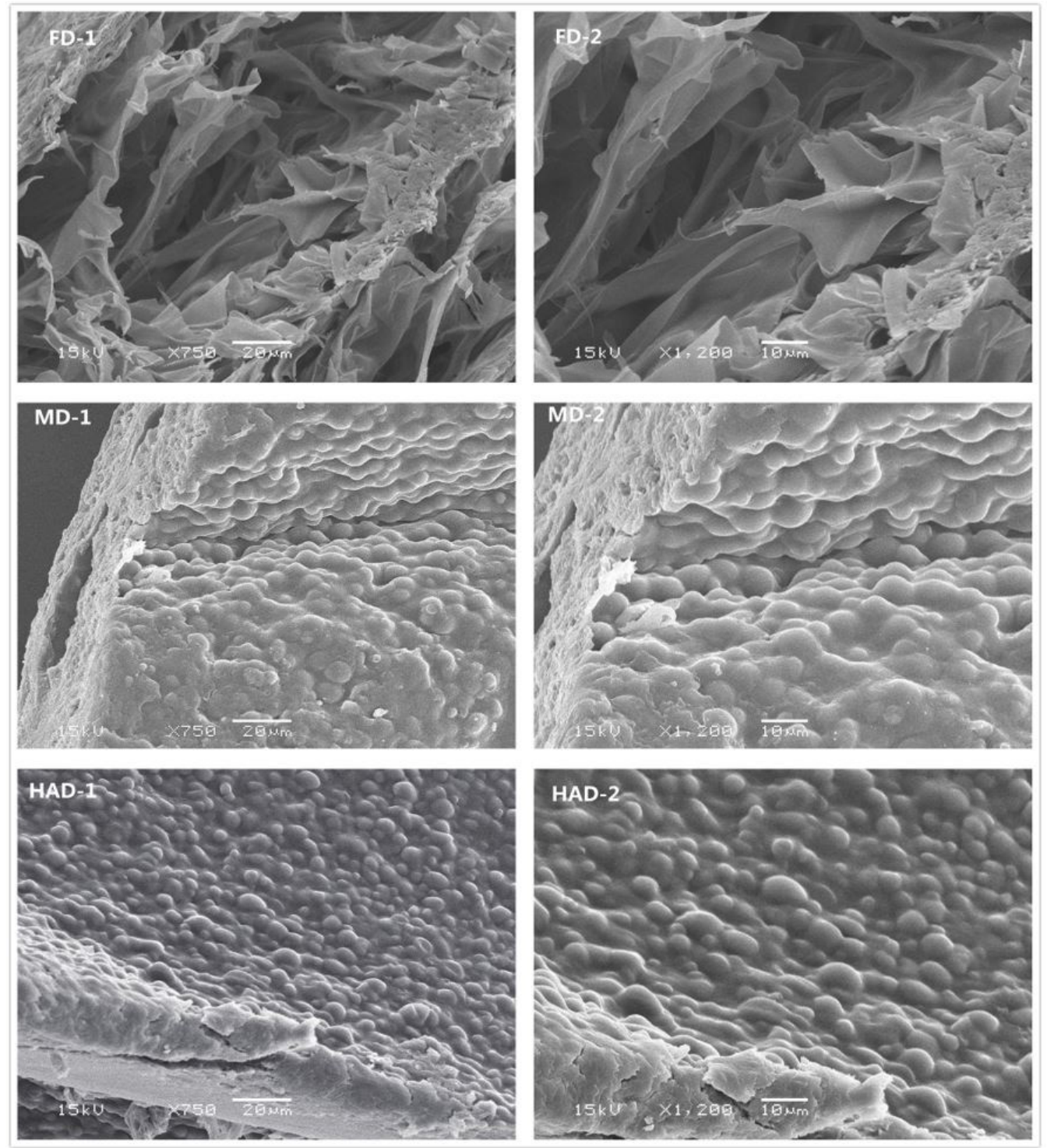

Figure 2. Scanning electron micrographs of instant T. fuciformis dried with FD (freeze drying), MD (microwave drying) and HAD (hot air dying). (1) magnification was set as $750 \times$; (2) magnification was set as $1200 \times$.

collapses under the action of gravity during the sublimation process, resulting in a slight contraction. On the other hand, the MD sample shrank most severely. This is mainly because the fruit body of T. fuciformis mushroom is composed of thin and wrinkled sheets. When moisture is transmitted from the inside of the T. fuciformis to the outside at a relatively fast speed during the microwave drying process, T. fuciformis sheets rapidly evaporate and rapidly shrink and overlap. Therefore, the overall shrinkage of the MD sample is large. This can be explained by the observation of the microstructure in Figure 2. HAD produced a $51.28 \%$ shrinkage of the sample, which was interpreted by as a long drying time giving more time for the product to shrink. This observation was similar to that made by Wang et al. (2014) and Tian et al. (2016). 


\subsection{Effects of different drying methods on rehydration ratio of dried instant T. fuciformis}

Consumers demand that the instant T. fuciformis, after adding hot water, not only can be eaten in a short time, but also its soup should be viscous and smooth from the polysaccharide of $T$. fuciformis, and the fruit body should be stretched and tender. Hence rehydration ratio is one of the important quality indicators of instant $T$. fuciformis products. The relationship between rehydration ratio and rehydration time was depicted in Figure 3, after drying instant T. fuciformis adding hot water of $90{ }^{\circ} \mathrm{C}$.

Figure 3 shows that the rehydration effects of dried instant T. fuciformis prepared by FD, MD and HAD are significantly different. The rehydration ratio of the product prepared by FD reached 10 or more in the first 6 minutes; however, after 15 minutes of adding hot water, the rehydration ratio of the MD sample did not exceed 4 , and the HAD one did not exceed 8 . These results were similar to the previous report of Monteiro et al. (2018), in which FD sample showed the highest rehydration ratio compared to the pumpkin slices prepared by other drying methods. The variations in the pore size of the dried food's internal structure impact on rehydration (Wang et al., 2014). The moisture sublimation of the FD might help T. fuciformis retain the porous structure. This will increase the efficiency of moisture penetration into the interior of the sample during rehydration. This porosity contributes to the highest rehydration ratio of the FD in the three drying methods. A severe shrinkage caused by microwaves occurred in the MD sample, and a hard crust on the surface of the product was also observed. In addition, intense heating might cause a greater change in the structure and composition of the T. fuciformis tissue during MD process. Therefore, the MD sample had the lowest rehydration ratio. HAD for a long time resulted in the T. fuciformis to shrink significantly and form a compact structure. This gave the sample a lower capacity to absorb water during rehydration. This observation was similar to that made by Tian et al. (2016) and Wang et al. (2014). But these results were not in agreement with the previous report of Öztürk \& Gündüz (2018), in which the sea cucumbers dried by FD, MD,

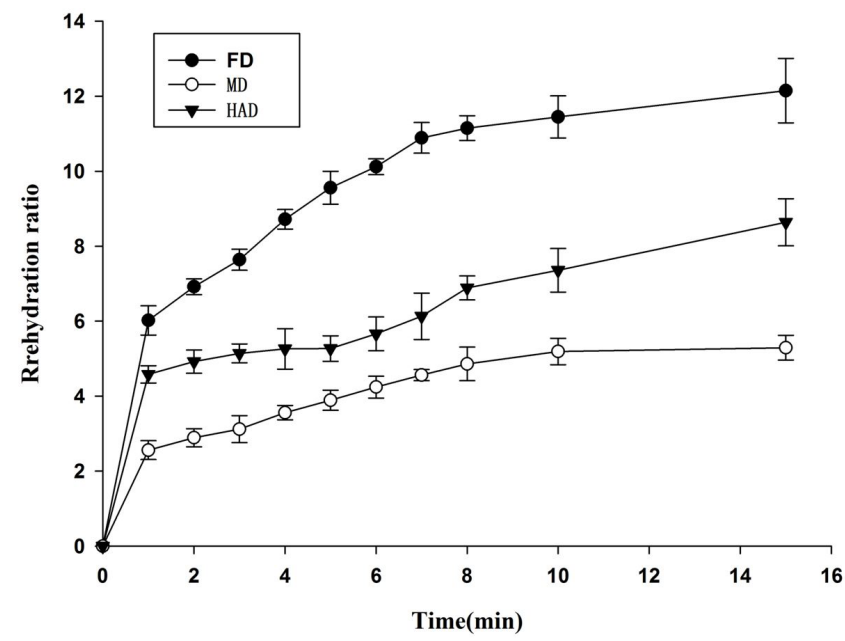

Figure 3. Rehydration ratio of instant T. fuciformis dried by FD (freeze drying), MD (microwave drying) and HAD (hot air dying). and HAD methods were showed to be of same quality in terms of rehydration ratio. This indicated that even if the same drying method was adopted, there were significant differences in the rehydration ratio of different dry materials.

\subsection{Effects of different drying methods on color of dried instant T. fuciformis}

Color is one of the important factors affecting the appearance of food and market acceptance. The drying treatment significantly affected the color of the instant T. fuciformis (Table 1). In general, the $L^{*}$ value (brightness), $a^{*}$ value (redness) and $b^{*}$ value (yellowness) of samples were increased to some extent after drying, and the differences were significant $(p<0.05)$. The FD products showed the largest the brightness value $L^{*}(81.50)$, followed by HAD products, while the MD samples had the smallest $L^{\star}$ value (69.99). The redness $a^{\star}$ value and the yellowness $b^{\star}$ value of the three kinds of dried instant T. fuciformis increased obviously, especially MD samples and HAD samples. The reason could be non-enzymatic browning, such as the Maillard reaction caused by amino acids and reducing sugars, and the caramelization caused by high temperature (Izli \& Isik, 2014). Additionally, the shrinkage of the T. fuciformis structure was one of the reasons for the change in color.

\subsection{Effects of different drying methods on viscosity and polysaccharide content of soup from dried instant T. fuciformis}

After the instant T. fuciformis products prepared by three drying methods adding $90{ }^{\circ} \mathrm{C}$ hot water for 15 minutes, the viscosity and polysaccharide content of the soup were measured (Figure 4).

The viscosity and polysaccharide content of the soup is one of the important indicators of the instant T. fuciformis products' quality. Figure 4 indicated that the drying method reduced the viscosity and polysaccharide content of the instant T. fuciformis soup $(p<0.05)$. Furthermore, there was a positive correlation between the viscosity and the polysaccharide content. The higher the polysaccharide content of the soup, the greater the viscosity value. FD had no significant effect on

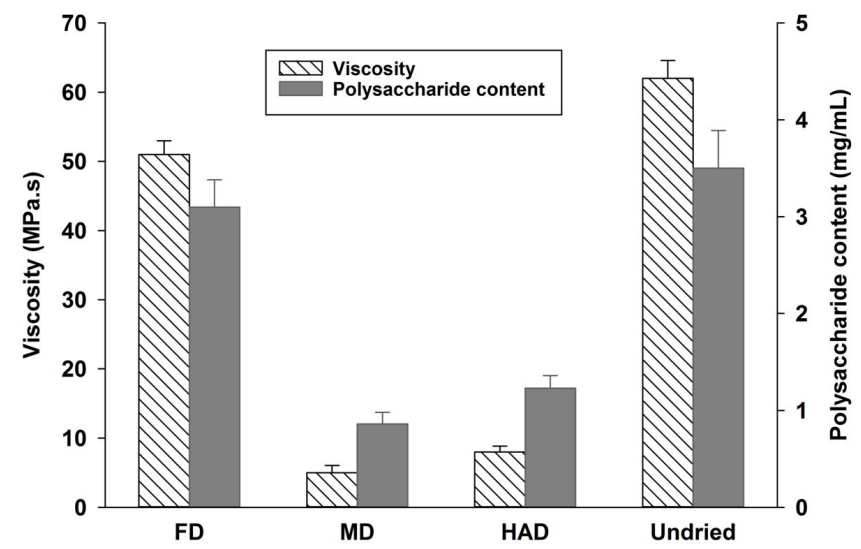

Figure 4. Viscosity and polysaccharide content of instant T. fuciformis soup. $\mathrm{FD}=$ freeze drying; $\mathrm{MD}=$ microwave drying; $\mathrm{HAD}=$ hot air dying. 
the two indicators, while MD and HAD decreased significantly. After adding $90^{\circ} \mathrm{C}$ hot water for $15 \mathrm{~min}$, the polysaccharide content of the FD sample soup was $3.12 \mathrm{mg} / \mathrm{mL}$, and the viscosity value was $51.46 \mathrm{mPa} \cdot \mathrm{s}$. FD preferably retained the polysaccharide component and viscosity of T. fuciformis, and the high temperature of hot air drying and microwave drying might destroy the structure and properties of polysaccharides. Moreover, the compact internal structure of the MD and HAD samples hindered moisture penetration, and the polysaccharide in the T. fuciformis cells was difficult to overflow. Various studies had illustrated that polysaccharides were the source of the viscosity and biological activity of Tremella fuciformis (Wu et al., 2019).

\subsection{Effects of different drying methods on microstructure of dried instant T. fuciformis}

The microstructure of the cross section and surface of the instant T. fuciformis dried by FD, MD and HAD, was observed by scanning electron microscopy (Figure 2). The drying method was indicated to have a strong impact on the microstructure of the dried product. The microstructure of sample obtained by FD was different obviously from MD and HAD. The cross-sectional structure of FD products was a three-dimensional network structure with porous, loose and large voids. The overall structure of the organization was relatively complete, and only a slight collapse occurred in some tissue. On the other hand, the inner of T. fuciformis prepared by MD and HAD formed a compact structure, and the internal tissue underwent severe shrinkage and deformation. This observation was similar to that made by Monteiro et al. (2018) and Jiang et al. (2017).

The above microstructure also confirmed the analysis results of the shrinkage ratio and rehydration ratio of the instant T. fuciformis product. The FD products possessed large tissue's voids, hence the fruit body of T. fuciformis was easier to stretch and had the better rehydration performance. The inner part of the T. fuciformis prepared by MD and HAD had a compact structure, and the structure collapsed and shrank, resulting in large shrinkage ratio and poor rehydration.

\subsection{Effects of different drying methods on protein, polysaccharide and reducing sugar content of dried instant T. fuciformis}

As Table 2 displayed that FD, MD and HAD significantly decreased the content of protein, uronic acid and reducing sugar in T. fuciformis $(p<0.05)$, but the content of polysaccharide from T. fuciformis prepared by FD was no significant difference before drying $(p<0.05)$. The protein content of FD products were not different from that of HAD $(p<0.05)$, and protein content of MD products were the lowest. The order of polysaccharide and uronic acid content of sample was: FD $>\mathrm{HAD}>\mathrm{MD}$, and the difference among them was significant. Many researchers have demonstrated that T. fuciformis polysaccharides possess various bioactivities, including anti-oxidation, anti-inflammatory and anti-tumors (Wu et al., 2019). It is worth noting that the efficacy of polysaccharides is closely related to the uronic acid content (Yan et al., 2019).

The use of different drying methods influenced significantly on the content of reducing sugar about instant $T$. fuciformis product (Table 2). FD sample had the highest content of reducing sugar, while the product prepared by HAD showed the smallest ones. This result might be related to the intense Maillard reaction presented by the HAD, which implied that the more intense condensation of the carbonyl group of a reducing sugar with an amino compound, resulting in the least content of reducing sugar.

Therefore, the drying method influenced on the nutrient content of the instant T. fuciformis product to some extent. FD basically retained the polysaccharide component of T. fuciformis, while MD and HAD obviously lost some of the nutrients and bioactive components. This could be that operating temperature was low during freeze drying, and the moisture of the sample was directly sublimated from the solid state to the gaseous state, resulting in a small damage to the cell structure and a slight degree of biochemical reaction. However, in the process of microwave drying and hot air drying, the degradation of carbohydrates, protein heat denaturation, Maillard reaction, and caramelization reaction were intense at high temperature, resulting in large loss of protein, amino acid and reducing sugar. Especially for microwave drying, the T. fuciformis had a fast heating speed and a high temperature, which was more destructive to nutrients.

\subsection{Effects of different drying methods on free amino acid contents of dried instant T. fuciformis}

T. fuciformis mushrooms contain a variety of amino acids. Table 3 indicated the changes in the composition and amount of free amino acids before and after drying under various drying methods. Glutamic acid (Glu) and Aspartic acid (Asp) showed higher amounts in the T. fuciformis mushroom samples. After the T. fuciformis mushrooms was dried, the Arginine (Arg) content and Leucine (Leu) content increased, the Glu content and the Alanine (Ala) content did not change, and the other 13 amino acid contents decreased significantly. Moreover, the total amino acid content, essential amino acids content, and non-essential amino acids content decreased significantly

Table 2. Effects of different drying methods on nutritional and functional components of instant T. fuciformis.

\begin{tabular}{|c|c|c|c|c|c|}
\hline Drying methods & $\begin{array}{l}\text { Moisture content } \\
(\mathrm{g} / 100 \mathrm{~g})\end{array}$ & $\begin{array}{l}\text { Protein content } \\
(\mathrm{g} / 100 \mathrm{~g})\end{array}$ & $\begin{array}{l}\text { Polysaccharide content } \\
(\mathrm{g} / 100 \mathrm{~g})\end{array}$ & $\begin{array}{l}\text { Uronic acid content } \\
(\mathrm{g} / 100 \mathrm{~g})\end{array}$ & $\begin{array}{l}\text { Reducing sugar } \\
\text { content }(\mathrm{g} / 100 \mathrm{~g})\end{array}$ \\
\hline FD & $3.12 \pm 0.23^{a}$ & $9.50 \pm 0.11^{b}$ & $38.35 \pm 0.89^{a}$ & $2.24 \pm 0.16^{b}$ & $3.78 \pm 0.21^{b}$ \\
\hline $\mathrm{MD}$ & $5.99 \pm 0.27^{c}$ & $8.82 \pm 0.25^{c}$ & $27.21 \pm 2.05^{\mathrm{d}}$ & $0.92 \pm 0.07^{\mathrm{d}}$ & $2.47 \pm 0.18^{c}$ \\
\hline HAD & $4.83 \pm 0.31^{b}$ & $9.06 \pm 0.17^{b c}$ & $33.43 \pm 2.30^{c}$ & $1.73 \pm 0.11^{c}$ & $1.68 \pm 0.14^{\mathrm{d}}$ \\
\hline Undried & $96.45 \pm 1.11^{\mathrm{d}}$ & $10.15 \pm 0.16^{\mathrm{a}}$ & $40.29 \pm 0.61^{\mathrm{a}}$ & $2.87 \pm 0.11^{a}$ & $5.23 \pm 0.22^{\mathrm{a}}$ \\
\hline
\end{tabular}

Data are presented as the mean $\pm \mathrm{SD}(\mathrm{n}=3)$. Values with different letters in the same column differ significantly $(p<0.05)$. FD = freeze drying; $\mathrm{MD}=$ microwave drying; $\mathrm{HAD}=\mathrm{hot}$ air dying. 
Table 3. Free amino acid content in instant T. fuciformis mushroom dried by different methods.

\begin{tabular}{|c|c|c|c|c|}
\hline & \multicolumn{4}{|c|}{ Content (g/100 g dry weight) } \\
\hline & FD & MD & HAD & Undried \\
\hline \multicolumn{5}{|l|}{ Essential amino acids } \\
\hline Arginine & $0.63 \pm 0.06^{\mathrm{a}}$ & $0.55 \pm 0.05^{\mathrm{b}}$ & $0.60 \pm 0.06^{\mathrm{ab}}$ & $0.56 \pm 0.05^{\mathrm{b}}$ \\
\hline Histidine & $0.21 \pm 0.02^{\mathrm{b}}$ & $0.20 \pm 0.03^{\mathrm{b}}$ & $0.21 \pm 0.03^{\mathrm{b}}$ & $0.28 \pm 0.03^{\mathrm{a}}$ \\
\hline Isoleucine & $0.42 \pm 0.03^{\mathrm{b}}$ & $0.39 \pm 0.02^{\mathrm{b}}$ & $0.40 \pm 0.03^{\mathrm{b}}$ & $0.56 \pm 0.04^{\mathrm{a}}$ \\
\hline Leucine & $0.61 \pm 0.07^{\mathrm{a}}$ & $0.60 \pm 0.06^{\mathrm{a}}$ & $0.60 \pm 0.04^{\mathrm{a}}$ & $0.56 \pm 0.06^{\mathrm{a}}$ \\
\hline Lysine & $0.57 \pm 0.07^{\mathrm{a}}$ & $0.47 \pm 0.03^{\mathrm{b}}$ & $0.51 \pm 0.03^{\mathrm{ab}}$ & $0.56 \pm 0.06^{\mathrm{a}}$ \\
\hline Methionine & $0.14 \pm 0.01^{\mathrm{b}}$ & $0.07 \pm 0.01^{\mathrm{c}}$ & $0.06 \pm 0.01^{\mathrm{c}}$ & $0.28 \pm 0.02^{\mathrm{a}}$ \\
\hline Phenylalanine & $0.41 \pm 0.03^{\mathrm{b}}$ & $0.41 \pm 0.03^{\mathrm{b}}$ & $0.39 \pm 0.03^{\mathrm{b}}$ & $0.56 \pm 0.05^{\mathrm{a}}$ \\
\hline Threonine & $0.47 \pm 0.04^{\mathrm{b}}$ & $0.47 \pm 0.04^{\mathrm{b}}$ & $0.48 \pm 0.03^{\mathrm{b}}$ & $0.56 \pm 0.06^{\mathrm{a}}$ \\
\hline Valine & $0.50 \pm 0.04^{\mathrm{ab}}$ & $0.48 \pm 0.04^{\mathrm{b}}$ & $0.48 \pm 0.03^{\mathrm{b}}$ & $0.56 \pm 0.07^{\mathrm{a}}$ \\
\hline Total essential amino acids & $3.97 \pm 0.24^{\mathrm{b}}$ & $3.65 \pm 0.17^{c}$ & $3.74 \pm 0.15^{\mathrm{c}}$ & $4.51 \pm 0.28^{\mathrm{a}}$ \\
\hline \multicolumn{5}{|l|}{ Non-essential amino acids } \\
\hline Alanine & $0.57 \pm 0.06^{\mathrm{a}}$ & $0.55 \pm 0.05^{\mathrm{a}}$ & $0.56 \pm 0.05^{\mathrm{a}}$ & $0.56 \pm 0.05^{\mathrm{a}}$ \\
\hline Asparaginic acid & $0.88 \pm 0.07^{\mathrm{b}}$ & $0.86 \pm 0.04^{\mathrm{b}}$ & $0.88 \pm 0.08^{\mathrm{b}}$ & $1.13 \pm 0.09^{\mathrm{a}}$ \\
\hline Cystine & $0.15 \pm 0.03^{\mathrm{b}}$ & $0.13 \pm 0.01^{\mathrm{b}}$ & $0.13 \pm 0.01^{\mathrm{b}}$ & $0.28 \pm 0.02^{\mathrm{a}}$ \\
\hline Glutamic acid & $1.16 \pm 0.09^{\mathrm{a}}$ & $1.11 \pm 0.12^{\mathrm{a}}$ & $1.16 \pm 0.10^{\mathrm{a}}$ & $1.13 \pm 0.10^{\mathrm{a}}$ \\
\hline Glycine & $0.48 \pm 0.05^{\mathrm{b}}$ & $0.46 \pm 0.06^{\mathrm{b}}$ & $0.46 \pm 0.03^{\mathrm{b}}$ & $0.56 \pm 0.03^{\mathrm{a}}$ \\
\hline Proline & $0.41 \pm 0.03^{\mathrm{b}}$ & $0.38 \pm 0.03^{\mathrm{b}}$ & $0.42 \pm 0.03^{\mathrm{b}}$ & $0.56 \pm 0.05^{\mathrm{a}}$ \\
\hline Serine & $0.49 \pm 0.04^{\mathrm{b}}$ & $0.48 \pm 0.03^{\mathrm{b}}$ & $0.49 \pm 0.05^{\mathrm{b}}$ & $0.56 \pm 0.05^{\mathrm{a}}$ \\
\hline Tyrosine & $0.33 \pm 0.03^{b}$ & $0.29 \pm 0.02^{\mathrm{b}}$ & $0.28 \pm 0.03^{\mathrm{b}}$ & $0.56 \pm 0.06^{\mathrm{a}}$ \\
\hline Total non-essential amino acids & $4.47 \pm 0.43^{\mathrm{b}}$ & $4.25 \pm 0.32^{\mathrm{b}}$ & $4.38 \pm 0.37^{\mathrm{b}}$ & $5.35 \pm 0.46^{\mathrm{a}}$ \\
\hline \multicolumn{5}{|l|}{ Taste characteristics } \\
\hline MSG-like & $2.04 \pm 0.16^{\mathrm{b}}$ & $1.97 \pm 0.16^{\mathrm{b}}$ & $2.04 \pm 0.18^{\mathrm{b}}$ & $2.25 \pm 0.19^{\mathrm{a}}$ \\
\hline Sweet & $2.01 \pm 0.19^{\mathrm{b}}$ & $1.96 \pm 0.20^{\mathrm{b}}$ & $2.00 \pm 0.18^{\mathrm{b}}$ & $2.25 \pm 0.20^{\mathrm{a}}$ \\
\hline Bitter & $2.93 \pm 0.29^{\mathrm{b}}$ & $2.71 \pm 0.24^{c}$ & $2.74 \pm 0.26^{c}$ & $3.38 \pm 0.28^{\mathrm{a}}$ \\
\hline Tasteless & $0.90 \pm 0.10^{\mathrm{b}}$ & $0.76 \pm 0.05^{\mathrm{c}}$ & $0.80 \pm 0.06^{c}$ & $1.13 \pm 0.12^{\mathrm{a}}$ \\
\hline Total free amino acids & $8.44 \pm 0.51^{\mathrm{b}}$ & $7.90 \pm 0.49^{c}$ & $8.12 \pm 0.46^{\mathrm{bc}}$ & $9.86 \pm 0.58^{\mathrm{a}}$ \\
\hline
\end{tabular}

Data are shown as mean \pm SD $(n=3)$. Means within a row with the same letter are not significantly different as indicated by Duncan's multiple range test $(p<0.05)$. FD $=$ freeze drying; $\mathrm{MD}=$ microwave drying; HAD = hot air dying; MSG-like = monosodium glutamate-like; Aspartic acid + Glutamic acid. Sweet, Alanine + Glycine + Serine + Threonine. Bitter, Arginine + Histidine +Isoleucine + Leucine + Methionine + Phenylalanine + Valine. Tasteless, Lysine + Tyrosine.

$(p<0.05)$ in the dried instant T. fuciformis mushroom after drying treatment. Undried samples showed the highest total free amino acids $(9.86 \mathrm{~g} / 100 \mathrm{~g})$, followed by FD products $(8.44 \mathrm{~g} / 100 \mathrm{~g})$, while MD mushrooms showed the lowest total free amino acids $(7.90 \mathrm{~g} / 100 \mathrm{~g})$, followed by HAD samples $(8.12 \mathrm{~g} / 100 \mathrm{~g})$. These results were in disagreement with the previous report of Tian et al. (2016), in which the contents of free amino acids of shitake mushrooms increased when samples were hot air dried, vacuum dried, microwave dried, or microwave vacuum drying as compared to fresh mushrooms. This might be related to the chemical composition and processing characteristics of the T. fuciformis and the shitake mushroom.

These free amino acids were classified into several classes according to their taste characteristics (Komata, 1969). The bitter components content of the samples were in the range of 2.71-3.38 g/100 g dry weight (Table 3), higher than those of monosodium glutamate-like components (1.97-2.25 g/100 g dry weight) and of sweet components (1.97-2.25 g/100 g dry weight). Both of the MSG-like and sweet components were responsible for flavor enhancement and sweetness in mushrooms (Chen, 1986). The differences between the three drying (FD, $\mathrm{MD}$ and $\mathrm{HAD}$ ) products of these two types of amino acids classifications were not significant.

\section{Conclusions}

The drying method significantly affected the physicochemical properties of the instant $T$. fuciformis. The MD and HAD caused the inner structure of the T. fuciformi to form a compact structure and a stacked arrangement, resulting in severe shrinkage and poor rehydration of the sample. Meanwhile, the red and yellow colour values of the MD and HAD samples rose sharply, and the polysaccharide, uronic acid, protein and amino acids were destroyed during MD and HAD. However, the instant T. fuciformis prepared by FD possessed a three-dimensional network with porous, loose and large voids, so the sample shrunk slightly and the rehydration effect was perfect. After adding $90^{\circ} \mathrm{C}$ hot water for $15 \mathrm{~min}$, the polysaccharide content of the FD sample soup was $3.12 \mathrm{mg} / \mathrm{mL}$, and the viscosity value was $51.46 \mathrm{mPa}$. Despite the decrease after drying, the total free amino acids of the FD product was higher than that of the other two drying methods. The products prepared by FD basically retained the nutrients of the T. fuciformis and obtained a good color. Hence, FD was a suitable method for preparing high-quality of instant $T$. fuciformis products. 


\section{Acknowledgements}

This work was supported by the National Key R\&D Program of China [Project No. 2018YFD0400203]; Fujian provincial department of science and technology, China [grant numbers 2018R1014-1, 2018R1014-6 and 2019J01116]; and Fujian Academy of Agricultural Sciences [grant numbers DEC201821204].

\section{References}

Chen, B. (2010). Optimization of extraction of Tremella fuciformis polysaccharides and its antioxidant and antitumour activities in vitro. Carbohydrate Polymers, 81(2), 420-424. http://dx.doi.org/10.1016/j. carbpol.2010.02.039.

Chen, H. K. (1986). Studies on the characteristics of taste-active components in mushroom concentrate and its powderization (Master's thesis). National Chung-Hsing University, Taichung, Taiwan.

Hu, J., Zhou, F., Lin, Y., Zhou, A., Tan, B. K., Zeng, S., Hamzah, S. S., \& Lin, S. (2019). The effects of photodynamically activated curcumin on the preservation of low alum treated ready-to-eat jellyfish. Lebensmittel-Wissenschaft + Technologie, 115, 108443. http://dx.doi. org/10.1016/j.lwt.2019.108443.

Izli, N., \& Isik, E. (2014). Effect of different drying methods on drying characteristics, colour and microstructure properties of mushroom. Journal of Food and Nutrition Research, 53(2), 105-116.

Jiang, N., Liu, C., Li, D., Zhang, Z., Liu, C., Wang, D., Niu, L., \& Zhang, M. (2017). Evaluation of freeze drying combined with microwave vacuum drying for functional okra snacks: antioxidant properties, sensory quality, and energy consumption. Lebensmittel-Wissenschaft + Technologie, 82, 216-226. http://dx.doi.org/10.1016/j.lwt.2017.04.015.

Lee, J., Ha, S. J., Lee, H. J., Kim, M. J., Kim, J. H., Kim, Y. T., Song, K. M., Kim, Y. J., Kim, H. K., \& Jung, S. K. (2016). Protective effect of Tremella fuciformis Berk extract on LPS-induced acute inflammation via inhibition of the NF-KB and MAPK pathways. Food \& Function, 7(7), 3263-3272. http://dx.doi.org/10.1039/C6FO00540C. PMid:27334265.

Li, Y. B., Wu, L., Weng, M. J., Tang, B. S., Lai, P. F., \& Chen, J. C. (2018). Effect of different encapsulating agent combinations on physicochemical properties and stability of microcapsules loaded with phenolics of plum (Prunus salicina lindl.). Powder Technology, 340, 459-464. http://dx.doi.org/10.1016/j.powtec.2018.09.049.

Lin, S., Chi, W., Hu, J., Pan, Q., Zheng, B., \& Zeng, S. (2017). Sensory and nutritional properties of chinese olive pomace based high fibre biscuit. Emirates Journal of Food and Agriculture, 29(7), 495-501. http://dx.doi.org/10.9755/ejfa.2016-12-1908.

Lin, Y., Hu, J., Li, S., Hamzah, S. S., Jiang, H., Zhou, A., Zeng, S., \& Lin, S. (2019). Curcumin-based photodynamic sterilization for preservation of fresh-cut Hami melon. Molecules (Basel, Switzerland), 24(13), 2374. http://dx.doi.org/10.3390/molecules24132374. PMid:31252525.

Komata, Y. (1969). The taste and constituents of foods. Nippon Shokuhin Kogyo Gakkaishi, 3, 26.

Monteiro, R. L., Link, J. V., Tribuzi, G., Carciofi, B. A. M., \& Laurindo, J. B. (2018). Microwave vacuum drying and multi-flash drying of pumpkin slices. Journal of Food Engineering, 232, 1-10. http://dx.doi. org/10.1016/j.jfoodeng.2018.03.015.

Nemzer, B., Vargas, L., Xia, X., Sintara, M., \& Feng, H. (2018). Phytochemical and physical properties of blueberries, tart cherries, strawberries, and cranberries as affected by different drying methods. Food Chemistry, 262, 242-250. http://dx.doi.org/10.1016/j. foodchem.2018.04.047. PMid:29751916.
Nguyen, T. K., Mondor, M., \& Ratti, C. (2018). Shrinkage of cellular food during air drying. Journal of Food Engineering, 230, 8-17. http://dx.doi.org/10.1016/j.jfoodeng.2018.02.017. PMid:29389609.

Ozcan-Sinir, G., Ozkan-karabacak, A., Tamer, C., \& Copur, O. (2019). The effect of hot air, vacuum and microwave drying on drying characteristics, rehydration capacity, color, total phenolic content and antioxidant capacity of Kumquat (Citrus japonica). Food Science and Technology, 39(2), 475-484. http://dx.doi.org/10.1590/fst.34417.

Ricci, E. C., Banterle, A., \& Stranieri, S. (2018). Trust to go green: an exploration of consumer intentions for eco-friendly convenience food. Ecological Economics, 148, 54-65. http://dx.doi.org/10.1016/j. ecolecon.2018.02.010.

Sehrawat, R., Nema, P. K., \& Kaur, B. P. (2018). Quality evaluation and drying characteristics of mango cubes dried using low-pressure superheated steam, vacuum and hot air drying methods. Lebensmittel-Wissenschaft + Technologie, 92, 548-555. http://dx.doi.org/10.1016/j.lwt.2018.03.012.

Singh, P. R., \& Heldman, D. R. (2014). Dehydration. In P. R. Singh \& D. R. Heldman (Eds.), Introduction to food engineering (5th ed., pp. 675-710). New York: Academic Press. http://dx.doi.org/10.1016/ B978-0-12-398530-9.00012-7.

Tian, Y., Zhao, Y., Huang, J., Zeng, H., \& Zheng, B. (2016). Effects of different drying methods on the product quality and volatile compounds of whole shiitake mushrooms. Food Chemistry, 197(Pt A), 714-722. http://dx.doi.org/10.1016/j.foodchem.2015.11.029. PMid:26617008.

Wang, H., Zhang, M., \& Mujumdar, A. (2014). Comparison of three new drying methods for drying characteristics and quality of shiitake mushroom (Lentinus edodes). Drying Technology: An International Journal, 32(15), 1791-1802. http://dx.doi.org/10.1080/07373937.2014.947426.

Wen, L., Gao, Q., Ma, C. W., Ge, Y., You, L., Liu, R. H., Fu, X., \& Liu, D. (2016). Effect of polysaccharides from Tremella fuciformis on UV-induced photoaging. Journal of Functional Foods, 20, 400-410. http://dx.doi.org/10.1016/j.jff.2015.11.014.

Wu, S., Li, F., Jia, S., Ren, H., Gong, G., Wang, Y., Lv, Z., \& Liu, Y. (2014). Drying effects on the antioxidant properties of polysaccharides obtained from Agaricus blazei Murrill. Carbohydrate Polymers, 103, 414-417. http://dx.doi.org/10.1016/j.carbpol.2013.11.075. PMid:24528748.

Wu, Y. J., Wei, Z. X., Zhang, F. M., Linhardt, R. J., Sun, P. L., \& Zhang, A. Q. (2019). Structure, bioactivities and applications of the polysaccharides from Tremella fuciformis mushroom: a review. International Journal of Biological Macromolecules, 121, 1005-1010. http://dx.doi.org/10.1016/j.ijbiomac.2018.10.117. PMid:30342120.

Yan, J., Zhu, L., Qu, Y., Qu, X., Mu, M., Zhang, M., Muneer, G., Zhou, Y., \& Sun, L. (2019). Analyses of active antioxidant polysaccharides from four edible mushrooms. International Journal of Biological Macromolecules, 123, 945-956. http://dx.doi.org/10.1016/j. ijbiomac.2018.11.079. PMid:30447375.

Yang, R., Jin, Z., Shen, T., Pu, L., \& Li, H. (2018). Tremella fuciformis polysaccharides attenuate oxidative stress and inflammation in macrophages through miR-155. Analytical Cellular Pathology, 2018, 8316-8324. http://dx.doi.org/10.1155/2018/5762371.

Zhou, Y., Chen, X., Yi, R., Li, G., Sun, P., Qian, Y., \& Zhao, X. (2018). Immunomodulatory effect of Tremella polysaccharides against cyclophosphamide-Induced immunosuppression in mice. Molecules, 23(2), 239. http://dx.doi.org/10.3390/molecules23020239. PMid:29370108.

Öztürk, F., \& Gündüz, H. (2018). The effect of different drying methods on chemical composition, fatty acid, and amino acid profiles of sea cucumber (Holothuria tubulosa Gmelin, 1791). Journal of Food Processing and Preservation, 42(9), e13723. http://dx.doi. org/10.1111/jfpp.13723. 